\title{
Adolescent and adult laryngotracheal stenosis: a review
}

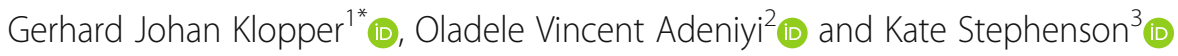

\begin{abstract}
Background: The larynx has multiple composite functions which include phonation, airway protection, and sensory control of respiration. Stenosis of the larynx and trachea were first recorded by O'Dwyer in 1885 and by Colles in 1886, respectively. Initially, the aetiology of laryngotracheal stenosis was predominantly infective. Currently, the leading cause is iatrogenic injury to the laryngotracheal complex secondary to prolonged ventilation in an intensive care unit.

Main body: Laryngotracheal stenosis is a complex and diverse disease. It poses a major challenge to the surgeon and can present as an airway emergency. Management typically demands the combined involvement of various disciplines including otorhinolaryngology, cardiothoracic surgery, anaesthesiology, interventional pulmonology, and radiology. Both the disease and its management can impact upon respiration, voice, and swallowing. The incidence of iatrogenic laryngotracheal stenosis has reflected the evolution of airway and intensive care whilst airway surgery has advanced concurrently over the past century. Correction of laryngotracheal stenosis requires expansion of the airway lumen; this is achieved by either endoscopic or open surgery. We review the relevant basic science, aetiopathogenesis, diagnosis, management, and treatment outcomes of LTS.

Conclusion: The choice of surgical procedure in the management of laryngotracheal stenosis is often dictated by the individual anatomy and function of the larynx and trachea, together with patient factors and available facilities. Regardless of how the surgeon chooses to approach these lesions, prevention of iatrogenic laryngotracheal damage remains of primary importance.
\end{abstract}

Keywords: Airway stenting, Endoscopic dilatation, Laryngotracheal stenosis, Laryngopharyngeal reflux, Laryngotracheoplasty, Laryngotracheal reconstruction

\section{Background}

The larynx has multiple complex functions including phonation, airway protection, and sensory control of respiration. LTS is an umbrella term referring to a group of conditions that result in luminal compromise of the central airway at the level of the glottis, subglottis, or trachea. Initially, the aetiology of LTS was predominantly infective. Currently, the leading cause is iatrogenic injury to the laryngotracheal complex secondary to prolonged ventilation in an intensive care unit (ICU). Other causes

\footnotetext{
* Correspondence: gjklopper1987@gmail.com

'Department of Otorhinolaryngology, Faculty of Health Sciences, Frere

Hospital/Walter Sisulu University, East London 5274, South Africa

Full list of author information is available at the end of the article
}

include trauma, neoplasms, connective tissue disorders, and idiopathic disease [1-3]. It is useful to consider paediatric and adult LTS as separate entities because their anatomy and physiology differ significantly [4]. Further distinction should be made between the following, as their management and outcomes differ $[1,5]$ :

- Immature/fibro-inflammatory and mature/cicatricial stenoses

- Low-grade (Meyer-Cotton I-II) and high-grade (Meyer-Cotton III-IV) stenoses

- Simple/single-level and complex/multi-level stenoses

- Supraglottic/glottic and subglottic/tracheal stenoses 
Although permanent tracheostomy remains the most straightforward method of managing the compromised airway in patients with LTS, it fails to meet optimum treatment goals. These include the following:

- The establishment and maintenance of airway patency

- The preservation or restoration of glottic competence

- The achievement of acceptable phonation [6]

\section{Main text}

\section{Epidemiology}

Iatrogenic airway injury has been demonstrated within hours of intubation. Esteller-Moré, et al. reported overt injury in $47 \%$ of patients bronchoscoped at extubation [7]. Only a minority of these patients develop cicatricial LTS; however, suggesting that the initial fibroinflammatory injury resolves in most cases. Notably, patients with indolent stenoses may be capable of accommodating over time by reducing their physical activity. This is in contrast to those that develop the same level of stenosis acutely, suffering significant disability. In the absence of high-quality follow-up data, it is plausible that some patients may experience a degree of stenotic dyspnoea that remains undiagnosed lifelong [2].

Although the true incidence of LTS remains unknown, the most cited study regarding its aetiology is that of Lorenz who estimated an incidence of between $1 \%$ and $4 \%$ for prolonged airway intubation [1]. Nevertheless, Nouraei, et al. acknowledge that determining the epidemiology remains challenging, as formal diagnosis is often delayed until specialist outpatient evaluation [2].

\section{Anatomical considerations}

The larynx starts at the laryngeal inlet and ends at the inferior border of the cricoid cartilage. It is divided anatomically into the supraglottis, glottis and subglottis. The glottis and subglottis are demarcated by a line drawn one centimetre below the free edge of the vocal folds. The subglottis ends where the cervical trachea begins, at the lower border of the cricoid cartilage. The tracheal cross-section is $\mathrm{D}$-shaped with incomplete $\mathrm{C}$ shaped cartilaginous rings. These rings both stiffen the tracheal wall and provide a degree of flexibility. The free posterior ends of the cartilages are embedded in the trachealis muscle. Each cartilage is enclosed in perichondrium, from which it receives nourishment.

The seminal works of Salassa, et al. defined the blood supply of the trachea [8]. The inferior thyroid artery supplies the cervical trachea via three branches which terminate by dividing into tracheal and oesophageal tributaries. The tracheal vessels ramify both cranially and caudally, anastomosing with their superior and inferior counterparts to form lateral longitudinal tracheal pedicles. It is from these pedicles that the entire blood supply of the lateral and anterior tracheal walls is derived. A rich capillary bed then arborises throughout the endotracheal submucosa, closely adherent to the luminal surfaces of the tracheal cartilages. This represents the only blood supply of the trachea as there are no capillary plexuses on its external surface. Endoluminal compression of this tenuous blood supply can therefore easily cause ischemic necrosis of the trachea. Tracheal patency relies upon the structural integrity of the cartilaginous framework.

There is some degree of inter-individual variability regarding the resilience of the airway to medical procedures. One explanation could be anatomical aberrations in the lateral longitudinal tracheal pedicles. Another might be compromised flow through these pedicles secondary to paratracheal fibrosis following trauma, transmural tracheal necrosis, previous surgery, or infection [8].

\section{Physiological considerations}

Three physiological principles determine airflow through the laryngotracheal complex:

1. Poiseuille's law

2. Reynold's number

3. The Venturi effect

The Hagen-Poiseuille equation demonstrates that resistance to airflow is inversely proportional to the fourth power of the airway radius:

$$
R=\frac{8 n l}{\pi r^{4}}
$$

( $R$ = resistance, $n=$ viscosity, $l=$ length, $r=$ radius)

A $50 \%$ reduction in airway radius would thus cause a 16-fold increase in resistance to airflow. Overcoming such resistance would increase the work of breathing. Airflow turbulence further compounds airway resistance and contributes to the work of breathing. Reynold's number describes the point at which airflow transitions from laminar to turbulent:

$$
N_{R e}=\frac{p v d}{\mu}
$$

$\left(N_{R e}=\right.$ Reynold's number, $p=$ density, $v=$ velocity, $d_{o}=$ diameter, $\mu=$ dynamic viscosity)

A Reynold's number of less than 2000 confers laminar flow, 1 between 2000 and 4000 mixed flow, and 1 above 4000 turbulent flow. This demonstrates that large airways are more prone to turbulent flow than smaller ones, with turbulence occurring at the point of transition from small to large diameter. Airflow turbulence would 
therefore occur just distal to a stenosis upon inspiration and just proximal to it upon expiration.

LTS may be further complicated by tracheomalacia. According to the Venturi effect (a derivation of Bernoulli's principle), when the velocity of airflow through a tube increases, its pressure decreases in order to keep the total energy contained within the system constant. This exerts an inwardly directed force upon its walls. Where the structural integrity of these walls is compromised (such as in tracheomalacia), the negative pressure causes inward mural collapse. This transforms a static lesion into a dynamic one, compounding the aforementioned physiological effects.

\section{Aetiopathogenesis of iatrogenic airway injury}

Iatrogenic airway injury occurs predominantly at the cuff of an airway tube where excessive inflation pressures cause mucosal necrosis and subsequent ulceration. Early endotracheal tubes (ETTs) had small volume, high pressure cuffs which generated high lateral wall pressures [9]. In response, large volume, low pressure cuffs were designed to achieve a clinical seal at low inflation pressures. These can still, however, be overinflated. Following extubation, epithelialisation begins at the edges of such an ulcer and is typically complete within 4 weeks. Fibrosis and metaplastic squamous epithelium then mark the site of previous injury. If the degree of ulceration was severe, or the recovery process delayed by secondary infection, increased tissue damage occurs. This may lead to aberrant wound healing with resultant LTS [10]. Of additional importance is the tube diameter. In a randomised controlled trial, Mathias and Wedley concluded (through endoscopic assessment of injury patterns) that excessive lateral wall pressure can equally be caused by oversized ETTs (standardised for cuff pressure) [11].

Although superficial damage occurs within $4 \mathrm{~h}$ of intubation, this only progresses with time when lateral wall pressures are sustained beyond $100 \mathrm{mmHg}$. Seegobin and Hasselt demonstrated that excessive lateral wall pressure causes not only direct mucosal damage, but also indirect damage through attenuation of capillary blood flow [12]. Capillary perfusion pressure ranges from $22 \mathrm{mmHg}$ to 32 $\mathrm{mmHg}$. Sustained lateral-wall pressure above $22 \mathrm{mmHg}$ significantly compromises mucosal blood flow. Vascular perfusion is completely obstructed by pressures above 37 mmHg. Therefore, while some contact-related mucosal damage is inevitable, the depth of such damage may be minimised by using a pressure limiting device or an inline manometer.

\section{Diagnosis and investigation History}

Relevant information includes previous intubation, character and duration of dyspnoea, voice changes, chronic cough, pyrosis, and any co-morbid medical illnesses. Dyspnoea should be graded according to the American Medical Research Council (MRC) Dyspnoea Scale (Table 1) [13], which demonstrates sensitivity to treatment-related changes in adult LTS with both convergent and divergent validity [14].

\section{General examination}

The severity of stridor and signs of respiratory distress should be documented. Mounting evidence implicates laryngopharyngeal reflux (LPR) in the aggravation of LTS $[15,16]$. Twenty-four-hour oesophageal $\mathrm{pH}$ monitoring remains the gold standard for diagnosing LPR. The Reflux Symptom Index (RSI) and Reflux Finding Score (RFS) are two validated clinical tools designed for the same purpose but with greater ease of clinical administration $[15,16]$. Additionally, voice should be evaluated pre- and post-treatment (e.g. by determining the maximum phonation time for the vowels /e/ and /a/, the vocal range profile, and the GRBAS (grade, roughness, breathiness, asthenia, strain) grading) [17].

\section{Special investigations}

Any lesion suspected to represent a connective tissue disease should be biopsied, with serological testing as appropriate [5]. According to Jewett et al., high definition computed tomography can aid in distinguishing intrinsic (intact laryngotracheal framework) from panmural stenosis (laryngotracheal framework deformed or collapsed) [18]. Intrinsic stenoses may benefit from endoscopic treatment whereas pan-mural or malacic stenoses generally require open surgery [5].

\section{Endoscopic evaluation}

The Laryngotracheal Stenosis Committee of the European Laryngological Society suggests the use of a standardised pre-operative assessment and classification system (Table 2) [5]. This serves to individualise treatment, promotes greater levels of success, and allows a more accurate comparison of clinical outcomes. The recommended system categorises LTS according to its pathophysiological characteristics (immature/fibro-inflammatory versus mature/cicatricial) as well as its complexity (simple/single-level versus complex/multi-level). The authors caution that lesions related to blunt and penetrating trauma, caustic injury, or inhalational burns might present classification difficulty owing to their extent of involvement.

Through a combination of radiography and endoscopy, an accurate assessment of the structural integrity of the cartilaginous framework can be made. Additionally, stenosis severity should be stratified according to the Myer-Cotton (Fig. 1), Lano (Table 3), or McCaffrey classifications (Table 4) [19-21]. 
Table 1 American Medical Research Council Dyspnoea Scale [13]

\begin{tabular}{ll}
\hline Grade I & Not troubled by breathlessness except with strenuous exercise. \\
Grade II & Troubled by shortness of breath when hurrying on the level or walking up a slight hill. \\
Grade III & Walks slower than people of the same age on the level because of breathlessness or has to stop for breath \\
Grade IV & When walking at own pace on the level. \\
Grade V & Stops for breath after walking about $100 \mathrm{~m}$ or after a few minutes on the level. \\
\hline
\end{tabular}

Used with the permission of the Medical Research Council [13]

\section{Quantifying the pathophysiological effects of LTS}

The mismatch between ventilatory effort and volume of air shifted that results from LTS causes a dissociation between efferent motor command and afferent sensory feedback [1]. This is perceived as abnormally effortful respiration, manifesting clinically as exertional dyspnoea.

Traditionally, spirometry has served as a non-invasive method of severity stratification in LTS, but is measured from total lung capacity and at maximal effort. Simulating conditions of heavy exercise rather than baseline activity, it does not correlate well with PROMs. In comparison, pressure-volume curves measure pulmonary compliance during conditions of tidal volume breathing and thus imitate the level at which most daily activities occur. This provides an objective and quantitative measure of the pathophysiological effects of airway stenosis, demonstrating robust correlation with the severities of both dyspnoea and anatomical disease [22]. Measuring pulmonary compliance in spontaneously breathing patients does however require intra-thoracic pressure monitoring using an oesophageal pressure transducer.

By calculating the minimum clinically important difference (MCID) values for flow-volume loops, Nouraei, et al. found a strong correlation between both change in total peak flow as well as area under the flow-volume curve: forced vital capacity ratio and changes in the MRC Dyspnoea Scale ( $\triangle M R C)$ [23]. The MCID is defined as the smallest change in a physiological variable that represents a significant change in an underlying clinical condition [24].

\section{Surgical management}

The management of LTS is complex and technically demanding owing to the structural characteristics of the larynx, coupled with the complexity of its functions [25]. Surgical techniques for LTS can be broadly classified as either endoscopic or open. Endoscopic procedures include:

- Balloon dilatation (occlusive/non-occlusive)

- Microsurgery/reconstruction

- Radial incision ('cold steel'/laser) and dilatation

- 'Endo-stenting' [25]

Open procedures include the following:

- Augmentation of the endoluminal diameter using tissue autografts/allografts (costal/thyroid cartilage)

- Resection of the stenotic segment with primary anastomosis (tracheal/cricotracheal resection)

Table 2 Five-step endoscopic airway assessment in LTS [5]

\begin{tabular}{lll}
\hline & Modality & Objective \\
\hline Step I & - Awake fibre-optic nasopharyngolaryngoscopy & - Dynamic assessment of laryngeal function \\
& - Topical anaesthetic & \\
Step II & - Fibreoptic nasopharyngolaryngoscopy & - Assessment of vocal fold mobility \\
& - Spontaneous respiration & - Assessment of upper airway patency \\
& - General anaesthetic & \\
Step III & - Transoral telescopic laryngo-tracheoscopy & - Assessment of LTS including anatomical site, mapping, cranio-caudal length and severity \\
& - Muscle relaxation & \\
- General anaesthetic & \\
Step IV & - Suspension micro-laryngoscopy & - Assessment of cricoarytenoid joint mobility \\
& - Supraglottic high-frequency jet-ventilation & - Assessment of LTS character (immature versus mature) \\
Step V & - Rigid/flexible bronchoesophagoscopy & - Assessment of the distal airway \\
& - Supraglottic high-frequency jet-ventilation & - Aspiration of tracheobronchial secretions for bacteriological investigation \\
& - Muscle relaxation
\end{tabular}

Adapted from: Monnier et al. [5] 

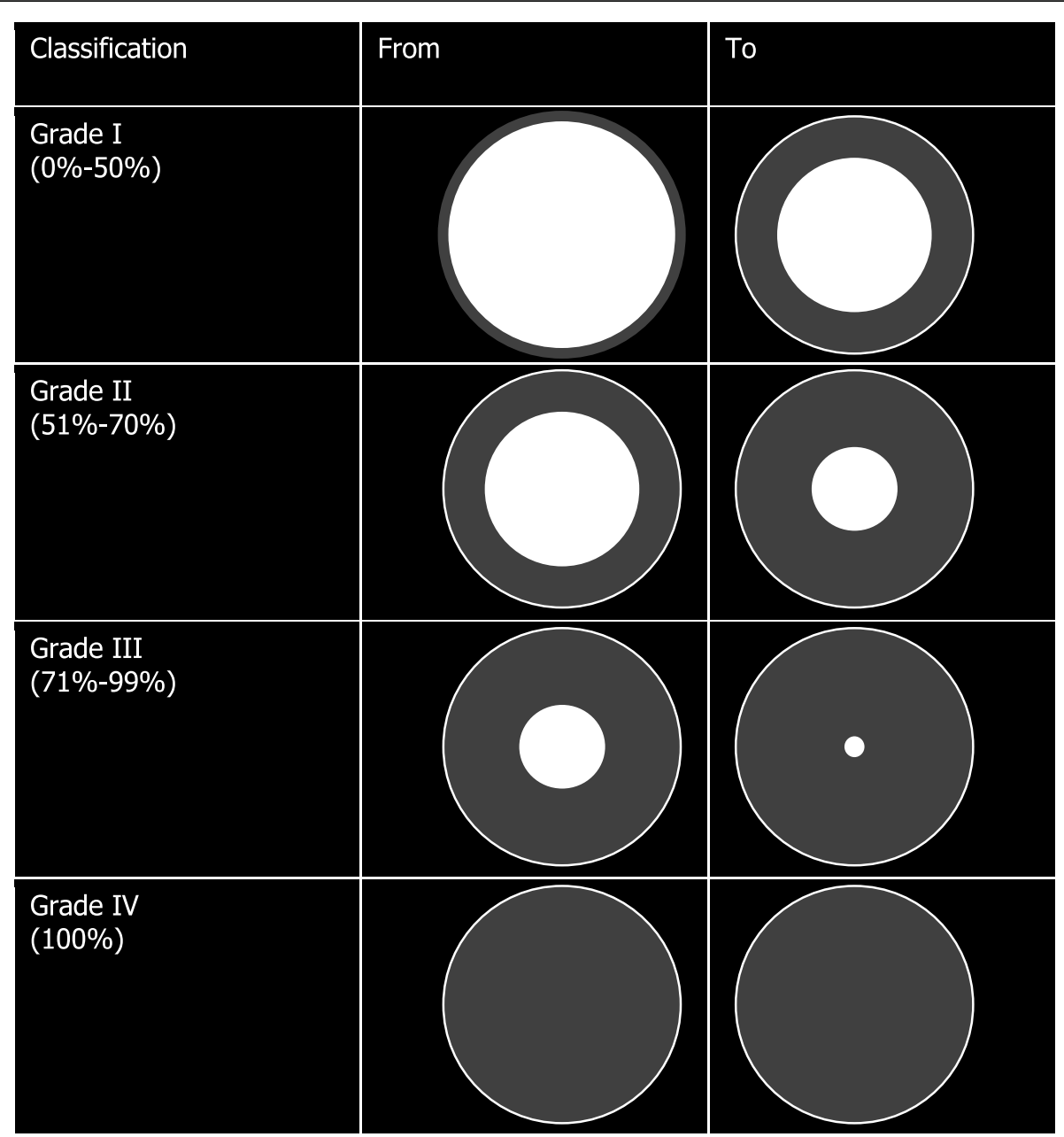

Fig. 1 Myer-Cotton classification [19]

- Manipulation of the airway framework (slide tracheoplasty) [26]

The choice of procedure should be tailored to the anatomy and function of the laryngotracheal complex, the performance status of the patient, and the availability of resources and expertise [27]. The Laryngotracheal Stenosis Committee of the European Laryngological Society recommends that mature/cicatricial high-grade adult stenoses be treated primarily by open surgery as the odds of success are generally highest for the first procedure [5].

\section{Table 3 Lano classification [20]}

\begin{tabular}{ll}
\hline Stage I & One subsite involved \\
Stage II & Two subsites involved \\
Stage III & Three subsites involved \\
\hline Source: Lano et al. $1998[20]$ &
\end{tabular}

\section{Endoscopic dilatation (Fig. 2)}

Advantages include its ease of access and low morbidity [28]. Immature/incipient fibro-inflammatory mucosal injuries generally respond well to endoscopic intervention, with the aim being prevention of cicatricial wound contracture and avoidance of a tracheostomy [2]. Appropriate candidates for primary endoscopic dilatation include lesions with a cranio-caudal length of less than $1 \mathrm{~cm}$ and those with adequate structural integrity of the cartilaginous framework. Relative contraindications include obesity and chronic LPR [25].

Table 4 McCaffrey classification [21]

\begin{tabular}{ll}
\hline Stage I & Subglottic or tracheal lesions $<1 \mathrm{~cm}$ long \\
Stage II & Subglottic lesions $>1 \mathrm{~cm}$ long \\
Stage III & Subglottic/tracheal lesions not involving the glottis \\
Stage IV & Glottic lesions \\
\hline
\end{tabular}

Source: McCaffrey, 1992 [21] 


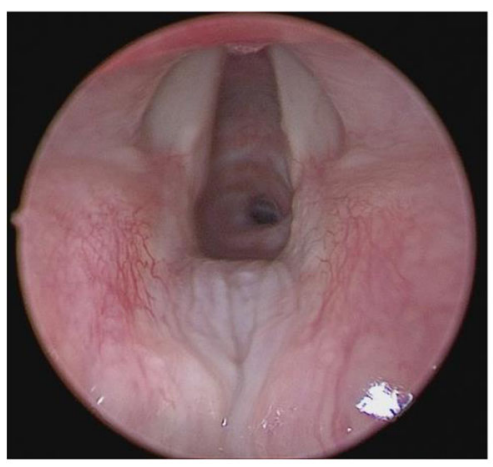

(a)

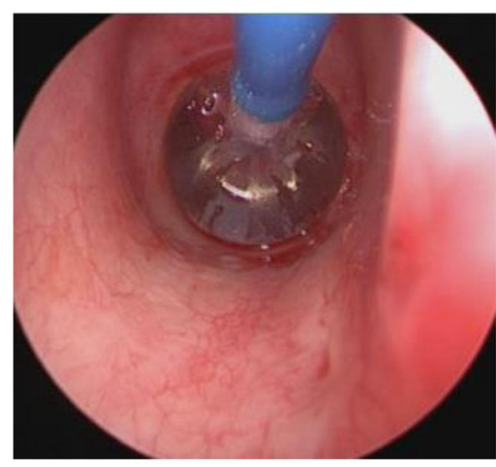

(b)

Fig. 2 Endoscopic photographs of airway stenoses

\section{Endoluminal augmentation}

Laryngotracheoplasty (LTP) remains a robust and consistently reproducible option for mature/cicatricial LTS [27]. The LTP has evolved substantially since its introduction by Rethi in 1956 [29]. Although minor modifications in technique are possible, a general description of the LTP is as follows: an anterior midline incision of the tracheal wall is made, often transecting the length of the stenotic tract in order to visualise a normal lumen above and below the lesion. If necessary, anterior or posterior cricoid splits may be performed, with interposition cartilage autografting, in order to maximise the airway lumen. Scar tissue excision may also be performed, depending on the residual structural integrity of the cartilaginous tracheal framework. The reconstruction is then requisitely stented for a period of time sufficient to allow healing such that the airway can be independently maintained. In 1995, Cotton et al. described the single-stage laryngotracheal reconstruction (SSLTR) in order to circumvent the complications of post-operative stenting [30]. SSLTR involves maintaining the airway postoperatively with an ETT as opposed to a prosthetic stent with a covering tracheostomy. Successful decannulation rates for SSLTR have been reported to range between $84 \%$ and $95 \%$ [30]. In comparison, the reported decannulation rates after airway expansion surgery as a whole range from 69 to $96 \%$ [31]. With regard to SSLTR, airway compromise post-decannulation may require reintubation, risking surgical site injury, and prolonging ICU time; this would negate some of the advantages gained through a single-stage procedure.

\section{Resection with primary anastomosis}

Developing in parallel to the LTP, tracheal resection with primary anastomosis was initially devised in 1969 by Grillo and refined by Pearson and Andrews [32]. In 1975, Pearson et al. described the partial cricoid cartilage resection with primary thyro-tracheal anastomosis and preservation of the recurrent laryngeal nerves [33]. Tracheal and partial cricotracheal resections evolved from these early procedures and currently represent the gold standard treatment for high-grade iatrogenic adult tracheal stenosis [34]. It is important to note, however, that these procedures are both resource and expertisedependent.

\section{Airway stenting}

Wright et al. consider active stenoses following burn and blast injuries, as well as severely disordered deglutition, absolute contra-indications to airway stenting in general [35]. Any endoluminal or intrinsic airway pathology that causes more than $50 \%$ reduction in lumen represents an indication for stenting. Further specific indications for stenting in LTS include:

- Maintenance of airway patency following debulking of intraluminal pathology

- Airway bolstering for compromised mural structural integrity (malacia)

- Treatment of anastomotic airway dehiscence or fistulisation

- Long-length stenoses

- Complex stenoses

- Failed reconstruction

- Contraindications to open surgery

- Patient preference

There are a variety of silicone and metallic airway stents, the latter either uncovered, partially covered (hybrid), or fully covered by polyurethane or Teflon ${ }^{\circledR}$. Metallic stents, introduced in 1952 by Hankins, are susceptible to metal fatigue which predisposes them to eventual fracture [36]. Furthermore, they become a permanent fixture within the airway if not removed timeously. Metallic stents should therefore be reserved for palliation. Since the introduction of the Montgomery ${ }^{\ominus}$ Safe-T-Tube ${ }^{\mathrm{TM}}$ (MST-T) (Fig. 3) in 


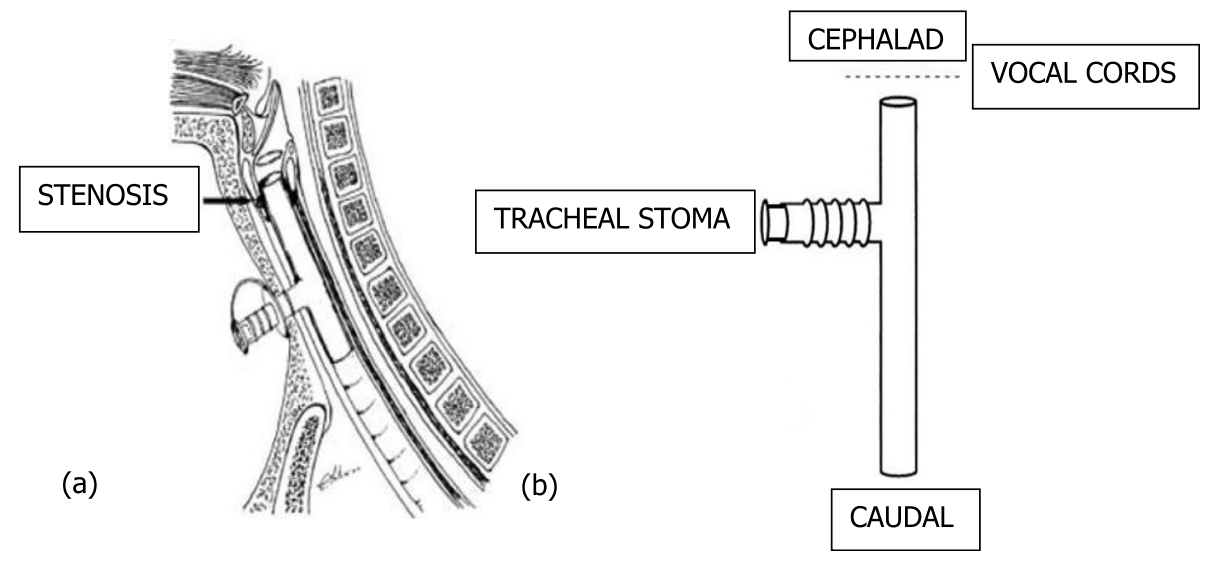

Fig. 3 The Montgomery ${ }^{\circledR}$ Safe-T-Tube ${ }^{T M}$ (Boston Medical Products, Inc.)

1965, silicone stents have continued to evolve, finding utility in a variety of locations throughout the airway [37]. There are now a variety of silicone stents suitable for use in LTS $[37,38]$.

Many authors agree that it is important to limit the duration of stenting, but consensus has not yet been reached and this also varies between stents [10, 31]. Stent removal requires general anaesthesia, with requisite costs and inherent risks. Removability and predisposition to long-term complications are thus major considerations when deciding on the choice of stent material.

General stent-related complications, which are often time-related, include granulation tissue formation, mucous plugging, microbial colonisation, and the initiation of an inflammatory tissue reaction if in contact with the caudal surfaces of the vocal cords [36, 38]. In an attempt to circumvent some of these complications, biodegradable (BD) stents have been designed and are currently in the process of refinement. These devices maintain airway patency for a predetermined length of time before gradually undergoing degradation and spontaneous resorption once no longer required. Several distinct synthetic, $\mathrm{BD}$ polymer classes have been approved for use in human application: polyesters containing lactic acid, glycolic acid, dioxanone or caprolactone, poly(trimethylene carbonates), polyanhydrides containing sebacic acid, and tyrosine-derived polyarylates. These base materials may be used in isolation or blended in the production of $\mathrm{BD}$ prostheses. The degradation resistance, and thus the mechanical property deterioration profile, corresponds to the type of polymer used or the combinations thereof. In this way, stents with different 'lifespans' can be made to achieve requisite stenting time-frames based on airway subsite and disease process. Five main kinds of $\mathrm{BD}$ implants are thus possible:
1. A device used for temporary artificial mechanical support when the natural tissue bed has been weakened by disease, injury, or surgery. The BD implant would provide this support until the natural tissue heals and regains its strength. A gradual stress transfer will occur with the BD implant gradually weakening as the natural tissue regains inherent strength.

2. Barrier devices used for interposition between tissues that must remain separated, for the prevention of post-surgical adhesions.

3. Implantable drug-eluting devices are capable of delivering drugs to specific locations over an extended period of time.

4. Tissue-engineering scaffolds are BD implants designed to facilitate growth and reorganisation into functional tissue by acting as an artificial extracellular matrix, allowing native cells the space for functional airway remodelling.

5. Multifunctional devices combine several of the above-mentioned functions within a single device.

Much literature exists on the application of these devices in animals and evidence from human studies is building. Galluccio et al. have shown that $70 \%$ of benign post-tracheostomy or post-intubation tracheal stenoses can be successfully treated with silicone stents if kept in situ for at least 18 months; this therefore represents the suggested benchmark for the longevity of the BD stents [39]. Although the introduction and deployment of these stents into paediatric as well as adult airways has been demonstrated to be both safe and user friendly, degradation time remains a major challenge with the BD stents, with the slowest degradation time being 14 months. Radial force is another important consideration as it determines the level of support offered to the stented airway, 
and the $\mathrm{BD}$ stents remain lacking when compared to metallic and silicone ones. Other safety concerns include the toxicity of their degradation products. Ideal indications for BD stents in human airways are yet to be defined [40].

\section{Medical management}

The management of LTS is primarily surgical, however, tailored medical management has a role in both perioperative optimisation and as an adjunct to surgery.

\section{Optimisation for surgery}

Animal studies have demonstrated that subglottic injuries exposed to acid and pepsin are less likely to heal than identical injuries not so exposed. May et al. found that patients with LTS had a $65 \%$ probability of having comorbid gastro-oesophageal reflux disease (GORD) [41]. Halstead reported that patients with LTS are 35\% less likely to require airway surgery when treated aggressively for GORD. It is suggested that patients be prescribed once or twice daily proton pump inhibitors as well as an alginate suspension after the evening meal. Additionally, any patient with symptomatic LPR should be investigated to assess the need for anti-reflux surgery. Any evidence of disordered deglutition warrants fibre-optic endoscopic evaluation of swallowing or videofluoroscopy as poor outcomes following airway surgery have been reported in patients with even minor aspiration [42]. It is also suggested that patients with airway stenosis be managed by a multidisciplinary team that includes an ENT, cardiothoracic surgeon, pulmonologist, anaesthetist, radiologist, pathologist, speech and swallowing therapist and dietician (as outcomes of airway surgery are known to be poorer in the obese) [42].

\section{Steroids}

The role of corticosteroids in airway surgery is with regards their anti-inflammatory, anti-fibroblastic activity, preventing scar formation and reducing the rate of recidivism. Although systemic steroids have a noteworthy side-effect profile, local steroid use demonstrates minimal systemic absorption and may aid in the perioperative management of LTS. Using suspension laryngoscopy, a long-acting steroid may be injected into a stenosis at the time of radial incision and dilatation. Alternatively, steroid impregnated pledgets or ointment can be applied before or after endoscopic interventions.

\section{Mitomycin-C}

Mitomycin-C (MMC), an antimitotic, cytotoxic chemotherapeutic agent derived from the bacteria Streptomyces caespitosus, has the ability to modify wound healing by interfering with chemotaxis and fibroblast proliferation [43]. MMC has been used topically with the aim of inhibiting tracheal scar formation after surgical airway reconstruction. There are no randomised controlled trials proving its efficacy, however, and continuing uncertainty regarding its long-term toxicity has led many clinicians to abandon its use.

\section{Outcomes}

Success in the treatment of LTS has been defined as the restoration of an airway lumen with subsequent decannulation and no further surgical requirement for at least 6 months [6,38]. Rates of success range from 67 to $96 \%$ $[20,31]$. Meta-regression analysis demonstrates the following individual success rates:

- $95 \%$ for resection with primary anastomosis

- $76 \%$ for LTP

- $40-82 \%$ for endoscopic surgery [25]

The high level of success with resection and primary anastomosis was confirmed in a subsequent systematic review by Lewis et al. in 2017 [44]. Notwithstanding the success rate, this procedure is technically demanding. An important complication is anastomotic dehiscence, the odds of which increase with resected lengths of greater than four centimetres. Longer segments require either laryngeal or pulmonary release to prevent excessive anastomotic tension. The majority of the literature regarding LTS is of an observational nature; this precludes a conclusion as to which treatment modality is superior [44].

Factors that affect clinical outcomes can be broadly classified into disease factors, patient factors and treatment factors [3, 23]. Additionally, Gelbard et al. suggest that these may have a summative effect [3].

\section{Aetiopathogenesis}

Different outcomes have been demonstrated for each aetiology (iatrogenic, idiopathic, autoimmune, and traumatic). Iatrogenic stenoses have the highest rates of post-interventional long-term tracheostomy dependence, which may be related to the high prevalence of tracheomalacia in this group [3].

\section{Anatomical disease severity}

The relationship between stenosis morphology and procedural outcomes has been established for LTS in both children and adults [4]. It has been demonstrated that with each additional percentage of luminal airway compromise (Myer-Cotton Classification) the odds of tracheostomy dependence increase by $3 \%[3,19]$. This is independent of surgical modality [43]. 


\section{Patient comorbidities}

Chronic comorbid disease is known to increase the risk of poor outcomes following airway surgery [28, 42]. Multivariate regression analysis demonstrates that each additional point on the Charlson Comorbidity Index (CCI) is associated with a $67 \%$ increase in odds of tracheostomy dependence [3]. The CCI is an index of 17 comorbidities assigned a weight from one to six depending on their risk of effecting one-year mortality [45]. Comorbidities demonstrating the strongest correlation to outcome in LTS are diabetes mellitus type II, myocardial infarction, congestive cardiac failure, peripheral vascular disease, cerebrovascular accident, gastroesophageal reflux, chronic obstructive pulmonary disease, and connective tissue disease [3].

\section{Complications}

The primary cause of treatment failure in LTS is post-surgical complications [46]. The most common complications are tracheomalacia and airway granulation tissue formation. Gustafson, et al. have devised a classification system to describe tracheomalacia severity (Table 5), with moderate to severe tracheomalacia representing a relative contraindication to single stage reconstruction [47].

Granulation tissue is commonly encountered during surgery for LTS [48]. It narrows the airway lumen and leads to progressive dyspnoea, which precludes both decannulation and definitive airway reconstruction. Granulation tissue heals by fibrosis, promoting stenotic recidivism. It is theorised to be driven by mechanical irritation, LPR, and the inflammatory response to polymicrobial colonisation [48]. Nouraei et al. have found the strength of correlation to be most robust with the microorganisms Staphylococcus aureus and Pseudomonas aeruginosa and recommend their eradication with Flucloxacillin and Ciprofloxacin, respectively [49].

\section{Conclusion}

Laryngotracheal stenosis is an extensive and complex topic. Disease management can be challenging and often involves multi-disciplinary care. Although treatment goals have been determined for the management of LTS [6], a clearly defined treatment algorithm has yet to be validated. Furthermore, there is no fixed treatment for LTS; the choice of surgical procedure is determined by

Table 5 Classification of tracheomalacia [47]

\begin{tabular}{ll}
\hline Absent & $0 \%$ respiration related airway occlusion \\
Mild & $1-33 \%$ respiration related airway occlusion \\
Moderate & $34-66 \%$ respiration related airway occlusion \\
Severe & $>66 \%$ respiration related airway occlusion \\
\hline
\end{tabular}

Source: Gustafson et al. 2000 [47] the individual anatomy and function of the larynx and trachea, together with patient factors and available facilities. Tissue engineering and tracheal allotransplantation may hold promise as future options in the management of these difficult cases and the use of biodegradable stents is evolving [40,50]. Regardless of how the surgeon chooses to approach these lesions, prevention of iatrogenic laryngotracheal damage remains of primary importance.

\section{Abbreviations \\ LTS: Laryngotracheal stenosis; ICU: Intensive care unit; ETT: Endotracheal tube; MRC: American Medical Research Council; LPR: Laryngopharyngeal reflux; RSI: Reflux Symptom Index; RFS: Reflux Finding Score; GRBAS: Grade, Roughness, Breathiness, Asthenia, Strain; MCID: Minimum clinically important difference; LTP: Laryngotracheoplasty; PROMs: Patient reported outcome measures; SSLTR: Single-stage laryngotracheal reconstruction; MST- T: Montgomery ${ }^{\circledR}$ Safe-T-Tube ${ }^{\text {TM}}$; BD: Biodegradable; GORD: Gastro- oesophageal reflux disease; MMC: Mitomycin-C; CCl: Charlson Comorbidity Index}

Acknowledgements

Not applicable

\section{Authors' contributions}

GJK, OVA, and KS. GJK was responsible for the requisite research and principal write-up of the manuscript. OVA was responsible for supervising the write-up of the manuscript, ensuring its scientific rigour. KS was responsible for reviewing the academic content of the manuscript, and contributed to its final write-up. The principle investigator (GJK) is prepared to take responsibility for the integrity of the content of the manuscript. All authors read and approved the final manuscript.

\section{Funding}

There is no funding to declare.

\section{Availability of data and materials \\ Not applicable}

\section{Declarations}

Ethical approval and consent to participate Not applicable

\section{Consent for publication}

Not applicable

\section{Competing interests}

The authors declare that they have no competing interests.

\section{Author details}

'Department of Otorhinolaryngology, Faculty of Health Sciences, Frere Hospital/Walter Sisulu University, East London 5274, South Africa.

${ }^{2}$ Department of Family Medicine, Faculty of Health Sciences, Cecilia Makiwane Hospital/Walter Sisulu University, East London, South Africa. ${ }^{3}$ Department of Otorhinolaryngology, Birmingham Children's Hospital, Steelhouse Lane, Birmingham B4 6NH, UK.

Received: 4 December 2020 Accepted: 7 April 2021

Published online: 21 April 2021

\section{References}

1. Lorenz RR (2003) Adult laryngotracheal stenosis: etiology and surgical management. Curr Opin Otolaryngol Head Neck Surg 11(6):467-472. https:// doi.org/10.1097/00020840-200312000-00011

2. Nouraei SA, Singh A, Patel A et al (2006) Early endoscopic treatment of acute inflammatory airway lesions improves the outcome of postintubation airway stenosis. Laryngoscope 116(8):1417-1421. https://doi.org/10.1097/01. mlg.0000225377.33945.14 
3. Gelbard A, Francis DO, Sandulache VC, Simmons JC, Donovan DT, Ongkasuwan J (2015) Causes and consequences of adult laryngotracheal stenosis. Laryngoscope 125(5):1137-1143. https://doi.org/10.1002/lary.24956

4. Grillo HC, Donahue DM, Mathisen DJ, Wain JC, Wright CD (1995) Postintubation tracheal stenosis: treatment and results. J Thorac Cardiovasc Surg 109(3):486-493. https://doi.org/10.1016/S0022-5223(95)70279-2

5. Monnier PH, Dikkers FG, Eckel H, Sittel C, Piazza C, Campos G, Remacle M, Peretti G (2015) Preoperative assessment and classification of benign laryngotracheal stenosis: a consensus paper of the European Laryngological Society. Eur Arch Oto Rhino Laryngol 272(10):2885-2896. https://doi.org/10.1 007/s00405-015-3635-4

6. Gallo A, Pagliuca G, Greco A, Martellucci S, Mascelli A, Fusconi M, de Vincentiis M (2012) Laryngotracheal stenosis treated with multiple surgeries: experience, results and prognostic factors in 70 patients. Acta Otorhinolaryngol Ital 32(3):182-188

7. Esteller-Moré E, Ibañez J, Matiñó E, Ademà JM, Nolla M, Quer IM (2005) Prognostic factors in laryngotracheal injury following intubation and/or tracheotomy in ICU patients. Eur Arch Oto Rhino Laryngol 262(11):880-883. https://doi.org/10.1007/s00405-005-0929-y

8. Salassa JR, Pearson BW, Payne WS (1977) Gross and Microscopical Blood Supply of the Trachea. Ann Thorac Surg 24(2):100-107. https://doi.org/10.1 016/50003-4975(10)63716-2

9. Carroll RG, McGinnis GE, Grenvik A (1974) Performance characteristics of tracheal cuffs. Int Anesthesiol Clin 12(3):111-131. https://doi.org/10.1097/ 00004311-197412030-00008

10. Bean JK, Verwoerd-Verhoef HL, Verwoerd CD (1995) Injury- and age-linked differences in wound healing and stenosis formation in the subglottis. Acta Oto-Laryngol 115(2):317-321. https://doi.org/10.3109/00016489509139319

11. Mathias DB, Wedley JR (1974) The effects of cuffed endotracheal tubes on the tracheal wall. Brit J Anaesth 46(11):849-852. https://doi.org/10.1093/ $\mathrm{bja} / 46.11 .849$

12. Seegobin RD, van Hasselt GL (1984) Endotracheal cuff pressure and tracheal mucosal blood flow: endoscopic study of effects of four large volume cuffs. BMJ 288(6422):965-968. https://doi.org/10.1136/bmj.288.6422.965

13. MRC Dyspnoea scale/MRC Breathlessness scale. [online]. Medical Research Council; 2020 [Accessed 2020 Jun 26]. Available at: http://www.mrc.ukri.org/ research/facilities-and-resources-for-researchers/mrc-scales/mre-dyspnoeascale-mre-breathlessness-scale/

14. Nouraei SA, Nouraei SM, Randhawa PS et al (2008) Sensitivity and responsiveness of the Medical Research Council dyspnoea scale to the presence and treatment of adult laryngotracheal stenosis. Clin Otolaryngol 33(6):575-580. https://doi.org/10.1111/j.1749-4486.2008.01832.x

15. Belafsky PC, Postma GN, Koufman JA (2001) The validity and reliability of the reflux finding score (RFS). Laryngoscope 111(8):1313-1317. https://doi.org/1 0.1097/00005537-200108000-00001

16. Belafsky P, Postma G, Koufman J (2002) Validity and reliability of the reflux symptom index (RSI). J Voice 16(2):274-277. https://doi.org/10.1016/S0892-1 997(02)00097-8

17. Hirano M (1981) Clinical examination of the voice. Disorders of Human Communication. Springer Verlag, New York 1-98.

18. Jewett BS, Cook RD, Johnson KL et al (1999) Subglottic stenosis: correlation between computed tomography and bronchoscopy. Ann Otol Rhinol Laryngol 108:837-841

19. Myer CM III, O'Connor DM, Cotton RT (1994) Proposed grading system for subglottic stenosis based on endotracheal tube sizes. Ann Otol Rhinol Laryngol 103(4):319-323. https://doi.org/10.1177/000348949410300410

20. Lano CF Jr, Duncavage JA, Reinisch L et al (1998) Laryngotracheal reconstruction in the adult: a ten-year experience. Ann Otol Rhinol Laryngol 107(2):92-97. https://doi.org/10.1177/000348949810700202

21. McCaffrey TV (1992) Classification of laryngotracheal stenosis. Laryngoscope 102(12):1335-1340. https://doi.org/10.1288/00005537-199212000-00004

22. Nouraei SM, Patel A, Virk JS, Butler CR, Sandhu GS, Nouraei SAR (2013) Use of pressure-volume loops for physiological assessment of adult laryngotracheal stenosis. Laryngoscope 123(11):2735-2741. https://doi.org/1 0.1002/lary.24061

23. Nouraei SM, Franco RA, Dowdall JR, Nouraei SAR, Mills H, Virk JS, Sandhu GS, Polkey M (2014) Physiology-based minimum clinically important difference thresholds in adult laryngotracheal stenosis. Laryngoscope 124(10):23132320. https://doi.org/10.1002/lary.24641

24. Make B (2007) How can we assess outcomes of clinical trials: the MCID approach. COPD 4(3):191-194. https://doi.org/10.1080/15412550701471231
25. Yamamoto K, Kojima F, Tomiyama K, Nakamura T, Hayashino Y (2011) Metaanalysis of therapeutic procedures for acquired subglottic stenosis in adults. Ann Thorac Surg 91(6):1747-1753. https://doi.org/10.1016/j.athoracsur.2011. 02.071

26. Abdelkafy WM, El Atriby MN, Iskandar NM et al (2007) Slide tracheoplasty applied to acquired subglottic and upper tracheal stenosis: an experimental study in a canine model. Arch Otolaryngol Head Neck Surg 133(4):327-330. https://doi.org/10.1001/archotol.133.4.327

27. Schmidt RJ, Shah G, Sobin L, Reilly JS (2011) Laryngotracheal reconstruction in infants and children: Are single-stage anterior and posterior grafts a reliable intervention at all pediatric hospitals? Int J Pediatr Otorhinolaryngol 75(12):1585-1588. https://doi.org/10.1016/j.jporl.2011.09.012

28. Tawfik KO, Houlton JJ, Compton W, Ying J, Khosla SM (2015) Laryngotracheal reconstruction: a ten-year review of risk factors for decannulation failure. Laryngoscope 125(3):674-679. https://doi.org/10.1002/lary.24963

29. Cotton RT, Mortelliti AJ, Myer CM (1992) Four-quadrant cricoid cartilage division in laryngotracheal reconstruction. Arch Otolaryngol Head Neck Surg 118(10):1023-1027. https://doi.org/10.1001/archotol.1992.01880100013005

30. Cotton RT, Myer CM III, O'Connor DM et al (1995) Pediatric laryngotracheal reconstruction with cartilage grafts and endotracheal tube stenting: the single-stage approach. Laryngoscope 105(8):818-821. https://doi.org/10.12 88/00005537-199508000-00009

31. Zalzal GH (1992) Stenting for pediatric laryngotracheal stenosis. Ann Otol Rhinol Laryngol 101(8):651-655. https://doi.org/10.1177/0003489492101 00804

32. Pearson FG, Andrews MJ (1971) Detection and management of tracheal stenosis following cuffed tube tracheostomy. Ann Thorac Surg 12(4):359374. https://doi.org/10.1016/S0003-4975(10)65137-5

33. Pearson FG, Cooper JD, Nelems JM, van Nostrand AWP (1975) Primary tracheal anastomosis after resection of the cricoid cartilage with preservation of recurrent laryngeal nerves. J Thorac Cardiovasc Surg 70(5): 806-816. https://doi.org/10.1016/S0022-5223(19)39664-3

34. George M, Lang F, Pasche P, Monnier P (2005) Surgical management of laryngotracheal stenosis in adults. Eur Arch Otorhinolaryngol 262(8):609-615. https://doi.org/10.1007/s00405-004-0887-9

35. Wright CD, Grillo HC, Wain JC, Wong DR, Donahue DM, Gaissert HA, Mathisen DJ (2004) Anastomotic complications after tracheal resection: prognostic factors and management. J Thorac Cardiovasc Surg 128(5):731739. https://doi.org/10.1016/j.jtcvs.2004.07.005

36. Ranu H, Madden BP (2009) Endobronchial stenting in the management of large airway pathology. Postgrad Med J 85(1010):682-687. https://doi.org/1 0.1136/pgmj.2009.089011

37. Montgomery WW, Montgomery SK (1990) Manual for use of Montgomery laryngeal, tracheal and oesophageal prostheses: update 1990. Ann Otol Rhinol Laryngol. Suppl 150:2-28

38. Dass A, Nagarkar NM, Singhal SK et al (2014) Tracheal T-Tube Stent for Laryngotracheal Stenosis: Ten Year Experience. Iran J Otorhinolaryngol 26(74):37-42

39. Galluccio G, Lucantoni G, Battistoni P, Paone G, Batzella S, Lucifora V, lacono $\mathrm{RD}$ (2009) Interventional endoscopy in the management of benign tracheal stenoses: definitive treatment at long-term follow-up. Eur J Cardiothorac Surg 35(3):429-433. https://doi.org/10.1016/j.ejcts.2008.10.041

40. Dutau H, Musani Al, Laroumagne S, Darwiche K, Freitag L, Astoul P (2015) Biodegradable airway stents - bench to bedside: a comprehensive review. Respiration 90(6):512-521. https://doi.org/10.1159/000442054

41. May JG, Shah P, Lemonnier L, Bhatti G, Koscica J, Coticchia JM (2011) Systematic review of endoscopic airway findings in children with gastroesophageal reflux disease. Ann Otol Rhinol Laryngol 120(2):116-122. https://doi.org/10.1177/000348941112000208

42. Nouraei SA, Ghufoor K, Patel A et al (2007) Outcome of endoscopic treatment of adult postintubation tracheal stenosis. Laryngoscope 117(6): 1073-1079. https://doi.org/10.1097/MLG.0b013e318050ca12

43. Roediger FC, Orloff LA, Courey MS (2008) Adult subglottic stenosis: management with laser incisions and mitomycin-C. Laryngoscope 118(9): 1542-1546. https://doi.org/10.1097/MLG.0b013e318179247a

44. Lewis S, Earley M, Rosenfeld R, Silverman J (2017) Systematic review for surgical treatment of adult and adolescent laryngotracheal stenosis. Laryngoscope 127(1):191-198. https://doi.org/10.1002/lary.26151.

45. Hall WH, Ramachandran R, Narayan S, et al (2004) An electronic application for rapidly calculating Charlson comorbidity score. BMC Cancer 4. Available from: https://doi.org/https://doi.org/10.1186/1471-2407-4-94. 
46. Jović RM, Dragičević D, Komazec Z, Mitrović S, Janjević D, Gašić J (2012) Laryngotracheal stenosis and restenosis. What has the influence on the final outcome? Eur Arch Oto Rhino Laryngol 269(7):1805-1811. https://doi.org/1 0.1007/s00405-012-1940-8

47. Gustafson LM, Hartley BE, Liu JH et al (2000) Single-stage laryngotracheal reconstruction in children: A review of 200 cases. Otolaryngol Head Neck Surg 123(4):430-434. https://doi.org/10.1067/mhn.2000.109007

48. Schmal F, Fegeler W, Terpe HJ et al (2003) Bacteria and grannulation tissue associated with Montgomery T-tubes. Laryngoscope 113(8):1394-1400. https://doi.org/10.1097/00005537-200308000-00024

49. Nouraei SA, Petrou MA, Randhawa PS et al (2006) Bacterial colonization of airway stents: a promoter of granulation tissue formation following laryngotracheal reconstruction. Arch Otolaryngol Head Neck Surg 132(10): 1086-1090. https://doi.org/10.1001/archotol.132.10.1086

50. Delaere PR, Vranckx J, Verleden G, de Leyn P, van Raemdonck D (2010)

Tracheal allotransplantation after withdrawal of immunosuppressive therapy. N Engl J Med 362(2):138-145. https://doi.org/10.1056/NEJMoa0810653

\section{Publisher's Note}

Springer Nature remains neutral with regard to jurisdictional claims in published maps and institutional affiliations.

\section{Submit your manuscript to a SpringerOpen ${ }^{\circ}$ journal and benefit from:}

- Convenient online submission

- Rigorous peer review

- Open access: articles freely available online

High visibility within the field

- Retaining the copyright to your article

Submit your next manuscript at $\boldsymbol{\nabla}$ springeropen.com 